\title{
Dissociative Disorder and its Relation to Stress among Adolescents
}

\author{
Eman Ahmed Shalaby El Khaiat ${ }^{1}$, Mona Hassan Abd Elaal ${ }^{2}$ and Doha Abd Elbaseer \\ Mahmoud $^{3}$ \\ (1) Bachelor of Nursing (2012),Nursing Specialist at Shibin El- Kom Hospital, Egypt, (2) Professor \\ of Psychiatric and Mental Health Nursing, Faculty of Nursing - British University in Egypt and (3) \\ Lecturer of Psychiatric and Mental Health Nursing, Faculty of Nursing, Benha University, Egypt
}

\begin{abstract}
Background: Dissociative disorder is a mental disorder that characterized by a disruption in the normal integration of consciousness, memory, emotion, perception, identity, body representation, motor control, and behavior. Aim of study: Was to assess dissociative disorder and its relation to stress among adolescents. Research design: A descriptive study design was utilized. Sample: A convenience sample composed of 572 students of first grade. Setting: The study was carried out at Faculty of Nursing at Benha University in Benha City. Tools of data collection: Three tools were used, I: A structured Interview Questionnaire about the socio-demographic data of studied adolescents. II: Dissociative Experience (DES) to assess the dissociative disorder and III Stress scale to assess stress. Results: Majority of studied sample have low level of total dissociative disorder and half of the studied students have moderate level of total stress. Conclusion: There is a significant positive correlation between total students dissociative disorder and their totals stress disorder. Recommendations: Psycho-educational program focused on the psychological, physiological and social needs of adolescents. Further studies for larger Sample should be done to generalized results.
\end{abstract}

Keywords: Adolescents, Dissociative disorder, Stress

\section{Introduction}

Dissociative disorder is a mental disorder that characterized by a disturbance in the normal integration of consciousness, memory, emotion, perception, identity, body representation, motor control, and behavior (American Psychiatric Association, 2017). People of any age, ethnicity, gender, and social background can develop dissociative disorder; Periods of dissociation can last for a relatively short time (hours or days) or for much longer (weeks or months). It can sometimes last for years, but usually if a person has other mental disorders such as depression or schizophrenia (Simeon et al., 2018).

The most significant risk factor for dissociative disorder is experiencing chronic stress, especially during adolescence, as well as experiencing or witnessing acute traumatic events. Adolescents with dissociative disorder escape from reality in ways that are involuntary and pathologically that cause problems with functioning in everyday life (Orchowski, 2020). There are four types of dissociative disorders, dissociative amnesia, depersonalization-derealization disorder, dissociative identity disorder (Formerly known as multiple personality disorder) and dissociative fugue. Although dissociative symptoms can be found in many mental disorders, highest levels of dissociative experiences were found in dissociative identity disorder (Lyssenko et al., 2018).

Adolescence is the phase of life between childhood and adulthood; some studies distinguish between early adolescence (From 11 or 12 to14 years), mid-adolescence (15-17 years) and late adolescence (18-21 years). Adolescents experience rapid physical, 
cognitive and psychosocial growth in this period. This affects how they feel, think, make decisions, and interact with the world around them. It is also a time to develop knowledge and skills, learn to manage emotions and relationships, and acquire attributes and abilities that will be important to the adolescent for enjoying the life (World Health Organization, 2020).

Adolescents with dissociative disorder are often misdiagnosed several times because they show signs, symptoms and behaviors that are characteristic of other important psychiatric disorders (psychosis, personality disorders, and mood and anxiety disorders. When Adolescents with dissociative disorder accurately diagnosed, they tend to respond well to specialized psychological treatments. On the other hand, incorrect or incomplete diagnosis may lead to consequently inappropriate treatment, including high-dose psychotropic medications and hospitalizations. Therefore, it is important that clinicians and researchers recognize symptoms that might suggest the presence of a complex dissociative disorder (Brand, 2017).

Dissociative disorder in adolescents is often known to be associated with stressful life events. Dissociation is often the psychological response to a traumatic event. Although not all traumatic events cause dissociation, trauma is frequently the main cause of dissociation for adolescents and adults. However, adolescents are more susceptible to trauma because their brains are still in development and they don't yet have the psychological flexibility that adults do. Their emotional and psychological foundations are already shaky, which makes them vulnerable to dissociation if trauma occurs (Nakatani, 2017).
Stress affects all body systems including nervous, cardiovascular, respiratory, musculoskeletal, immune, gastrointestinal, endocrine and reproductive systems (McEwen, 2017). Stress induced cardiovascular diseases include hypertension, myocardial ischemia, myocardial infarction and sudden cardiac death. Stress also induces respiratory changes like increase in respiratory rate, dyspnea. Chronic exposure to stress causes prolonged increase in muscle tension and promotes musculoskeletal disorders (Lindegard, 2017). The muscles of shoulders, neck and jaw, accessory muscles of respiration and diaphragm are commonly affected due to stress (Christmann, 2018).

Nurse encourage adolescent to identify methods of coping with stress and determine whether the response was adaptive or maladaptive. Nurse enhances adolescent's self-esteem through provide positive reinforcement for adolescent's attempts to change. Positive reinforcement enhances selfesteem and encourages repetition of desired behaviors. Nurse encourage adolescent to participate in activities such as art, music and sport (Vermetten, 2018).

Nurse enhance adolescent to learn distress tolerance skills that make the adolescent to be able to tolerate with painful emotions and uncomfortable feelings without resorting to impulsive and unhealthy behavior like dissociation. The aim of distress tolerance is to increase the adolescents' capacity to bare the painful emotion when the situation cannot be changed immediately. First, nurse learn the adolescents the role of emotions in life, the consequences of resisting them and how to identify and label an emotion. Once the adolescents learn this emotional first-aid, they start to feel relatively confident and safe in the face of an emotion because now they have tools to manage them (Spiegel, 2018). 


\section{$\underline{\text { Dissociative Disorder and its Relation to Stress among Adolescents }}$}

\section{Significance of the Study}

Dissociative experiences are common in our daily lives in the general population, ranging from mild to severe detachment, affects approximately $2-18 \%$ of individuals in the general population (Sar,etal. 2014). Few mental health professionals receive systematic training in the assessment and treatment of trauma related psychological problems, and even fewer about traumatized individuals who have dissociative reactions (Cook, et al. 2016). In light of this, increasing knowledge of the relationship between dissociative disorders and stress among adolescents is imperative.

Dissociative disorders can disrupt every area of psychological functioning, including consciousness, memory, identity, emotion, perception, body representation, motor control, and behavior, by leading to discontinuity in the normal integration of these functions. Due to their relation to childhood psychological traumatization and high level of psychiatric complications such as chronic depression, substance abuse, and suicidality, dissociative disorders constitute a public health issue (Sar, 2017).

\section{Aim of the study}

The study aimed to assess dissociative disorder and its relation to stress among adolescents.

\section{Research Question:}

Is there a relationship between dissociative disorder and stress among Adolescents?

\section{Subject and methods}

Research design

A descriptive study design was utilized to fulfill the aim of this study.

\section{Setting}

The study was carried out at faculty of nursing at Benha University in Benha City. Total numbers of first grade students were 860 students.

\section{Sampling:}

\section{Sample technique:}

A Convenient sample of first grade students in faculty of nursing at Benha University. The estimated sample size is 572, at confidence level $95 \%$ and precision rate at 0.025 by using (Thompson equation, 2012). Since the total number of them is 860 students.

$$
n=\left[\frac{N \times p(1-p)}{\left[N-1 \times\left(d^{2} \div z^{2}\right)\right]+p(1-p)}\right]
$$

\section{Inclusion criteria:-}

- Late adolescents.

- Both sexes.

- Willing to participate in this study.

\section{Tools for data collection:}

In order to fulfill the aim of the study, the data was collected by using the following tools.

Tool (I): A structured Interview Questionnaire:

This questionnaire was developed by the researcher after reviewing the related literature.

\section{Tool (II): Dissociative Experience Scale (DES)}

This scale was developed by (Putnam and Bernstein, 1986). This scale is composed of 27 items designed to assess the severity of dissociative disorder.

\section{Scoring system:}

The Dissociative Experience Scale is not a diagnostic instrument. It is a screening instrument. Each answers being scored on a scale value of 0 to 2 . Scoring system of Dissociative Experience Scale was categorized as follows:-

High score of dissociative disorder is indicated by 30 or more, low score of dissociative disorder is indicated by under 30, The high score have dissociative disorder and low score not have dissociative disorder. 
Tools (III): Stress scale.

This scale was developed by (Jacop, 2005). It has been translated into Arabic and tested for reliability and validity by (Hassanin, 2018). It's used to measure psychosocial stress; it consisted of 25 items in the form of likart scale using psychological, physiological, social and spiritual areas of stress.

\section{Scoring system:}

Positive and negative statements were included in the scale. The response alternatives were always, sometimes, rarely and never. These responses score as 1, 2, 3 and 4 for positive items and 4, 3, 2 and1for negative items.

Positive statements (12statements): 1, 2, 3, 4, $5,6,7,14,15,18,19$ and 24 .

Negative statements (13statements): 8, 9, 10, $11,12,13,16,17,20,21,22,23$ and 25.

Scoring system of stress scale was categorized as follows:

- $50-60 \%$ Mild.

- $61-70 \%$ Moderate.

- $>70 \%$ Severe.

\section{Validity of tools:}

To achieve the criteria of trustworthiness of the data collection tools in this study, tools were tested and evaluated for content validity. Arabic translation was done by the researcher for tools of the study and tested for their translation. Content validity was tested by three experts in psychiatric mental health nursing in faculty of nursing at Benha University. According to their opinions modifications were done and the final form was developed. The modification were (modify some words to give the right meaning of the phrase).

\section{Reliability of tools:}

Reliability was applied by the researcher for testing the internal consistency of the tools, by administration of the same subjects under similar conditions on one or more occasions. To ascertain relevance, clarity and completeness of the tools, experts elicited responses, which were either agree or disagree for the content reliability. Reliability test for Dissociative Experience Scale was 0.81 and 0.84 for stress scale.

\section{Ethical consideration:}

The objective and aim of the study were clarified by the researcher to every participant in the study, oral consent obtained from each student before conducting the interview; and given them a brief orientation to the purpose of the study. The subjects who agreed to participate in the study were assured about the confidentiality of the study. They were informed that they could withdrawal from the study at any time.

\section{Pilot study:}

The purpose of the pilot study was to test the applicability, feasibility and clarity of the tools. In addition, it served to estimate the approximate time required for interviewing the students as well as to find out any problems that might interfere with data collection. A pilot study was under taken after the adaptation of the tools and before starting the data collection. It was conducted on $(10 \%)$ 57 first grade students. After obtaining the result of the pilot study, the necessary modifications of tools were done then final format was developed under the guidance of supervisors. Students who participated in the pilot study were excluded in the main study sample.

\section{Fieldwork:}

The study was started and finished through the following steps:

- The researcher introduced herself to the students

- The researcher explained the aim of the study to every one of them. 


\section{Dissociative Disorder and its Relation to Stress among Adolescents}

- Oral Consent was taken from every one of them before data collection.

- The researcher visited faculty of nursing 3/ days per weeks.

- The actual filed work was carried out in about 3 months from October 2020 to the end of December 2020. The researcher visited the faculty of nursing at Benha city from 9 am to $3 \mathrm{pm}$, 3days per week to collect data from students.

- An individual interview conducted for every participant to collect the necessary data using the tools for data collection. The average time needed for this sheet was around (20-25) minutes.

\section{Statistical analysis:}

All data collected were organized, coded, computerized, tabulated and analyzed by using statistical package for social science (SPSS) programs version 20.Data were presented using descriptive statistics in the form of frequencies and percentage for categorical data, the arithmetic mean $(\mathrm{X})$ and standard deviation (SD) for quantitative data. Qualitative variables were compared using chi square test (X) 2, P-value to test association between two variables and $\mathrm{R}$ - test to the correlation between the study variables.

Degrees of significance of results were considered as follows:

- P-value >0.05 Not significant (NS)

- P-value $\leq 0.05$ Significant $(\mathrm{S})$

- P-value $\leq 0.01$ highly statistically Significant (HS).

\section{Results}

Table (1): Shows that, the Mean SD of age of the studied students is $18.41 \pm 2.08$ years. As regard to sex, two thirds $(66.8 \%)$ of the studied students are females. In addition, more than three quarters $(79.7 \%)$ of them were residing in rural areas.
Table (2): Shows that, $14 \%$ of the studied students have high level of total dissociative disorder. The mean of total dissociative disorder is $17.63 \pm 3.98$.

Figure (1): Shows that, $86 \%$ of the studied students have low level of total dissociative disorder, while, $14 \%$ of them have high level.

Table (3): Shows that, less than half (48.1\% and $49.7 \%)$ of the studied students have moderate level of psychological stress and social stress, respectively. Also, half $(50.5 \%)$ of them have moderate level of physiological stress. While, less than three quarters $(73.4 \%)$ of the studied students have low level of spiritual stress.

In addition, half $(50 \%)$ of the studied students have moderate level of total stress. Also, less than one quarter $(23.8 \%)$ of them have high level of stress. While, more than one quarter (26.2\%) of them of the studied students have low level of total stress.

Figure (2): Shows that, half $(50 \%)$ of the studied students have moderate levels of total stress. Also, less than one quarter $(23.8 \%)$ of them have high level. While, more than one quarter $(26.2 \%)$ of them of the studied students have low level of total stress.

Table (4): Indicate that, there is highly significant positive correlation between students' psychological stress, physiological stress and social stress at $(\mathrm{P}=<0.01)$. while, there is no significant correlation between students' spiritual stress and their psychological stress, physiological stress and social stress at $(\mathrm{P}=>$ 0.05).

Table (5): Indicate that, there is significant positive correlation between total students' dissociative disorder and their total stress disorder at $(\mathrm{P}=<0.01)$. 
Eman Ahmed Shalaby, Mona Hassan Abd Elaal and Doha Abd Elbaseer Mahmoud

Table (1): Frequency distribution of the studied students according to their personal $\operatorname{data}(n=572)$

\begin{tabular}{|c|c|c|}
\hline \multirow[t]{2}{*}{ Personal data } & \multicolumn{2}{|c|}{$<<(n=572)$} \\
\hline & $\mathbf{N}$ & $\%$ \\
\hline \multicolumn{3}{|l|}{ Age } \\
\hline 18 yrs. $<20$ yrs. & 564 & 98.6 \\
\hline$\geq 20$ yrs. & 8 & 1.4 \\
\hline Mean SD & \multicolumn{2}{|c|}{$18.41 \pm 2.08$} \\
\hline \multicolumn{3}{|l|}{ Sex } \\
\hline Male & 190 & 33.2 \\
\hline Female & 382 & 66.8 \\
\hline \multicolumn{3}{|l|}{ Residence } \\
\hline Rural & 456 & 79.7 \\
\hline Urban & 116 & 20.3 \\
\hline
\end{tabular}

Table (2): Frequency distribution of the students according to their total dissociative disorder $(\mathbf{n}=\mathbf{5 7 2})$

\begin{tabular}{|l|l|l|}
\hline Total dissociative disorder & \multicolumn{2}{|l|}{$(\mathbf{n}=\mathbf{5 7 2})$} \\
\cline { 2 - 3 } & $\mathbf{N}$ & $\mathbf{\%}$ \\
\hline High & 80 & 14 \\
\hline Low & 492 & 86 \\
\hline \multicolumn{2}{|l|}{ Mean $\mathbf{n}$ SD } & $\mathbf{1 7 . 6 3} \pm \mathbf{3 . 9 8}$ \\
\hline
\end{tabular}

\section{Total Dissociative Disorder}

Figure (1): Percentage distribution of the studied students according to their total dissociative disorder $(\mathbf{n = 5 7 2})$ 


\section{$\underline{\text { Dissociative Disorder and its Relation to Stress among Adolescents }}$}

Table (3): Frequency distribution of the students according to their total stress disorder $(\mathbf{n}=\mathbf{5 7 2})$

\begin{tabular}{|l|l|l|l|l|l|l|}
\hline \multirow{2}{*}{ Stress subscales } & \multicolumn{4}{|l|}{$(\mathbf{n}=\mathbf{5 7 2})$} & \multicolumn{3}{l|}{} \\
\cline { 2 - 8 } & \multicolumn{2}{|l|}{ Low } & \multicolumn{2}{l|}{ Moderate } & \multicolumn{2}{l|}{ High } \\
\cline { 2 - 8 } & $\mathbf{N}$ & $\mathbf{\%}$ & $\mathbf{N}$ & $\mathbf{\%}$ & $\mathbf{N}$ & $\mathbf{\%}$ \\
\hline Psychological subscale & 152 & 26.6 & 275 & 48.1 & 145 & 25.3 \\
\hline Physiological subscale & 163 & 28.5 & 289 & 50.5 & 120 & 21 \\
\hline Social subscale & 166 & 29 & 284 & 49.7 & 122 & 21.3 \\
\hline Spiritual subscale & 420 & 73.4 & 92 & 16.1 & 60 & 10.5 \\
\hline Total stress disorder & $\mathbf{1 5 0}$ & $\mathbf{2 6 . 2}$ & $\mathbf{2 8 6}$ & $\mathbf{5 0}$ & $\mathbf{1 3 6}$ & $\mathbf{2 3 . 8}$ \\
\hline
\end{tabular}

\section{Total strees disorder}

Figure (2): Percentage distribution of the studied students according to their total stress disorder $(\mathbf{n}=572)$

Table (4): Correlation between students' stress disorder subscales $(n=572)$

\begin{tabular}{|l|l|l|l|}
\hline Items & $\begin{array}{l}\text { Psychological } \\
\text { subscale }\end{array}$ & $\begin{array}{l}\text { Physiological } \\
\text { subscale }\end{array}$ & Social subscale \\
\hline $\begin{array}{l}\text { Physiological } \\
\text { subscale }\end{array}$ & $\begin{array}{l}\mathrm{r}=.378 \\
\mathrm{P}=.000^{* *}\end{array}$ & & \\
\hline Social subscale & $\mathrm{r}=.325$ & $\mathrm{r}=.333$ & \\
& $\mathrm{P}=.005^{* *}$ & $\mathrm{P}=.001^{* *}$ & $\mathrm{r}=.112$ \\
Spiritual subscale & $\mathrm{r}=.095$ & $\mathrm{r}=.081$ & $\mathrm{P}=.099$ \\
\hline
\end{tabular}

No significant at $p>0.05$. **highly significant at $p<0.01$.

Table (5): Correlation between students' dissociative disorder and stress disorder $(\mathbf{n}=572)$

\begin{tabular}{|l|l|}
\hline Items & Total Dissociative disorder \\
& \\
\hline Total stress disorder & $\begin{array}{l}\mathrm{r}=.210 \\
\mathrm{P}=.011^{*}\end{array}$ \\
\hline
\end{tabular}

*Significant at $\mathbf{p}<\mathbf{0 . 0 5}$. 


\section{Discussion}

Dissociative disorders are mental disorders that involve experiencing a disconnection and lack of continuity between thoughts, memories, surroundings, actions and identity. Dissociative disorders in adolescents develop as a reaction to a traumatic stress. Dissociation is viewed as an adaptive coping mechanism which keeping the adolescents safe by momentarily removing them from perceived stress in their day to day life, but dissociation leads to a range of behaviors which can often be misunderstood by adults as daydream, being a liar, or problems with concentration and causing disruption in every area of psychological functioning including consciousness, memory, identity, emotion, perception, body representation, motor control, and behavior (Rafiq, 2018).

Therefore, the present study aimed to explore the relationship between dissociative disorder and its relation to stress among adolescents. This aim was achieve through assessing the dissociative disorder and stress among adolescents and assessing the relation between stress and dissociative disorder among adolescents.

Regarding to personal characteristics of studied students, this study illustrated that more than two third of studied students are female. From the investigator point of view it may be due to differences in gender physiological predispositions, in which female would have a higher vulnerability to stress, than male. Females are more sensitive to others' reactions over their successes and failures compared to boys. This result is consistent with Allison, (2019) who showed that most of his sample around two thirds were females.

Also, the present study revealed that more than half of studied sample live in rural areas. From the investigator point of view it may be due to the fact of lack of mental and psychiatric health services. This result is similar to Garg, (2017) who showed that most of his sample around two thirds were females and live in rural areas. In contrast to that Harvey, (2018) who reported that dissociative disorders are related to posttraumatic stress disorder occurring as dysfunctional stress responses regardless of age, sex or residence of living.

Concerning to total dissociative disorder of the studied students. This study revealed that minority (less than one quarter) of the studied students has high level of total dissociative disorder. This study is consistent with Choi et al., (2017) who showed that less than of one quarter of the studied students have high level of total dissociative disorder. In contrast to that, Goffinet,(2018)who showed that three quarter of studied adolescent had pathological dissociative symptoms.

Concerning to total stress disorder among studied students. It showed that less than half of the studied students have moderate level of psychological stress and social stress, respectively. From the investigator point of view it may be due to lack of social skills in adolescence period. This result is in agreement with Roekel et al., (2018) who showed that more than half of studied adolescents had moderate degree of social stress. Also, this study showed that half of studied students had moderate level of physiological stress. From the investigator point of view it may be due to lack of stress response regulation by combination of brain and endocrine system to prevent body from negative effect of severe stress. This result is in agreement with Krapić et al., (2018) who showed that half of studied adolescents had moderate degree of physiological stress. In addition to study result, this study revealed that less than three quarters of the studied students have low level of spiritual stress. From the investigator point of view regarding to our culture it may be due to the increasing in religious awareness in our society. This 


\section{$\underline{\text { Dissociative Disorder and its Relation to Stress among Adolescents }}$}

study is consistent with Dawood and Yousaf (2016) who showed that three quarters of the studied adolescents had low level of spiritual stress.

Concerning correlation between students' stress disorder subscales, this study revealed that there is highly significant positive correlation between students' psychological stress, physiological stress and social stress at $(\mathrm{P}=<0.01)$. From the investigator point of view it may be due to when adolescent exposure to social stress such as (aggressive social interaction ,social evaluation), this social stress affect psychological status of the adolescent(anger, irritability, restlessness, Trouble sleeping, Problems with memory or concentration), then body respond to psychosocial stress through neuroendocrine system in which brain send impulses to pituitary gland and adrenal gland to release cortisol and adrenaline hormone for stress response regulation. It is consistent with Minkley et al., (2017) who showed that majority of studied sample who exposed to psychosocial stressors reported higher rate of physiological response, such as (increased in cortisol level, adrenaline level and heart rate).

Concerning to Correlation between students' dissociative disorder and stress disorder. This study revealed that there is significant positive correlation between total students' dissociative disorder and their total stress disorder. From the investigator point of view it may be due to the adolescent is still less emotionally stable and does not have social and emotional regulation skills that enable adolescent to be able to cope with stress, therefore in the time of stress this adolescent use the dissociative disorder as a coping mechanism in which allows the adolescent to distance themselves from a trauma that may be unbearable. This result is similar to Shah,(2018) who studied dissociative disorder and showed that majority of his sample who had dissociative disorder was young female of lower socioeconomic status with history of stressful life events.

\section{Conclusion:}

Majority of studied sample has low level of total dissociative disorder. Half of the studied students have moderate level of total stress. There is significant positive correlation between total Students dissociative disorder and their totals stress disorder at $(\mathrm{P} \leq 0.01)$.

\section{Recommendation}

\section{1- Recommendations aiming at community:}

- Psycho-educational program focused on the psychological, physiological and social needs of adolescents.

- Stress management program for all adolescents concerning with how to cope with Stress.

- Screening test should be done for all adolescents for early diagnosis and management of dissociative disorder.

- All Community sectors should be engaged in mental disorders prevention strategies, especially prevention programs of dissociative disorder in adolescents.

2. Recommendations aiming at nursing field:

- Psychiatric mental health nurse should provide health education to all parents who have adolescents with dissociative disorder which focused on signs and symptoms, causes and treatment of dissociative disorder for enable parents to deal with their sons.

- Nurse should provide counseling therapy to all adolescents with dissociative disorder concerning with stress management, avoid using dissociation as a coping mechanism with stress.

\section{Recommendation aiming at research}

- Further studies for larger Sample should be done to generalized results. 
- Studies about dissociative disorder in childhood stage should be done for early prevention of this disorder in adolescence period and later in adulthood.

\section{References}

Allison, K. (2019).Psychological dissection of patients having dissociative disorder: A cross-sectional study. Indian journal of psychological medicine 40 (1), 41-46.

American Psychiatric Association (2017). Diagnostic and statistical manual of mental disorders (5th Ed), dissociative disorder. Washington, DC, USA: American Psychiatric association.

Brand, B. (2017). A longitudinal naturalistic study of patients with dissociative disorders treated by community clinicians. Psychological Trauma: Theory, Research, Practice, and Policy, (5) 301-308. doi:10.1037/a0027654.

Choi, K. R., Seng, J. S., Briggs-King, E. C., Munro-Kramer, M. L., Graham-Bermann, S. A., Lee, R., \& Ford, J. D. (2017). The Dissociative Subtype of Posttraumatic Stress Disorder (PTSD) Among Adolescents: CoOccurring PTSD, Depersonalization/ Derealization, and Other Dissociation Symptoms. Journal of the American Academy of Child \& Adolescent Psychiatry. Doi: https://doi.org/10.1016/j. jaac.2017.09.425

Christmann, M. (2018). Musculoskeletal stress syndrome, extrinsic laryngeal muscles and body posture: theoretical considerations.. Article in Revista CEFAC · October 2018, (16):1639-1649.DOI:

10.1590/19820216201410613.

Cook, J. Dinnen,. S, Rehman, O, Bufka, L., Courtois, C., (2016). Responses of a sample of practicing psychologists to questions about clinical work with trauma and interest in specialized training. Psychological Trauma: Theory, Research, Practice, and Policy 3: 253-257. 2. Courtois CA, Gold SN (2016).

Dawood, S. and Yousaf, $H$ (2016).Spiritual Well-Being and Coping Styles in relation to
Psychological Well-being of Adolescents Corpus ID: 201913002. Dissociation Symptoms. Journal of the American Academy of Child \& Adolescent Psychiatry. doi:https://doi.org/10.1016/j. jaac.2016.09.425. Elsevier. pp. 562-569. Encyclopedia of the Social \& Behavioral Sciences, 2nd edition, Vol 23. Oxford:

Garg, R. (2017). Adolescent coping with everyday stressors: a seven-nation study of youth from central, eastern, southern, and northern Europe. European Journal of Developmental Psychology 4 (2), 129156, DOI: $10.1080 / 17405620600831564$

Goffinet S.J, (2018). Prevalence of dissociative symptoms in adolescents psychiatric inpatients. European Journal of Trauma \& Dissociation, 2018: (2), 39-45. DOI: 10.1016/J.EJTD.2017.10.008

Harvey, L. (2018). Posttraumatic stress disorder: a model of the longitudinal course and the role of risk factors. Journal of Clinical Psychiatry( 61), 15-23.

Hassanin, H.A. (2018). "Effect of Psychoeducational program on Psychological stress and quality of life among patients with hepatitis c virus ".Egyptian Journal of health care. $\quad$ March, 2018,(9): 94-107. DOI: 10.21608/EJHC.2018.13941.

Jacop,V.(2005)."Effectiveness of guided imagery in reduction of stress among patients with chronic illness in aselected hospital in mangalore. American Journal of Nursing Research. 6(6), 380-387. DOI: 10.12691/ajnr6-6-5

Krapić, N., Hudek-Knežević, J., Kardum, I., (2018). Stress in Adolescence: Effects on Development. International Encyclopedia of the Social \& Behavioral Sciences. Oxford: Elsevier. (23) 562-569. ISBN: 9780080970868

Lindegard, A. (2017). The influence of perceived stress and musculoskeletal pain on work performance and work ability in Swedish health care workers. International Archives of Occupational and Environmental 


\section{Dissociative Disorder and its Relation to Stress among Adolescents}

Health. $\quad 2017, \quad 87(4): \quad 373-379$. Doi: $10.1007 / \mathrm{s} 00420-013-0875-8$.

Lyssenko, L., Schmahl, C., Bockhacker, L., Vonderlin, R., Bohus, M., \& Kleindienst, N. (2018). Dissociation in psychiatric disorders: A meta-analysis of studies using the Dissociative Experiences Scale. American Journal of Psychiatry, 175, 37-46

McEwen, B. (2017). Central effects of stress hormones in health and disease: Understanding the protective and damaging effects of stress and stress mediators. European Journal of Pharmacol. 2017: (58)174-185.

Minkley, N., Schröder, T. P., Wolf, O. T., \& Kirchner, W. H. (2017). Effects of repeated administration of a combined physiological and psychological stressor. Psycho neuro endocrinology,(45), 119-127.Doi: 10.1016/j. psyneuen.

Nakatani, Y. (2017). Dissociative disorders: from Janet to DSM-IV. Seishin Shinkeigaku Zasshi 2017; 102(1):1-12. PMID: 10810882 . Available at https://pubmed.ncbi.nlm.nih.gov /10810882.

Orchowski, L. (2020). Dissociative disorder. Ferri's Clinical Advisor 2021 E-Book: 5 Books in 1, El-sevier data base, clinical key. p 479-480.

Putnam, F. \& Bernstein, E. (1986). Development, reliability and Validity of adissociation scale. "Journal of mental Disease .1986(12):727-35.

Rafiq, S. (2018). The relationship between childhood adversities and dissociation in severe mental illness: a metaanalytic review. Acta Psychiatric Scand, 2018, (138): 509525. DOI: 10.1111/acps.12969.

Roekel,V. , Verhagen,M \&Kuntsche,E. (2018). Social stress in early adolescents' daily lives: Journal of Clinical Child and Adolescent Psychology, 47,(2):888-899.
Sar, v., (2017). "Dissociative Disorder: Epidemiology" SAGE publication 2017 http://www.sagepub.com .p1:3.

Sar, V., O* nder, C., Kilincaslan, A., Zoroglu, S., \& Alyanak, B. (2014). Dissociative identity disorder among adolescents: Prevalence in a university psychiatric outpatient unit. Journal of trauma \& dissociation: the official journal of the International Society for the Study of Dissociation, 15, 402-419.

Shah ,S.K,(2018). A study of clinicodemographic profile of patients with dissociative disorder, Journal of College of Medical Sciences-Nepal, 2018, Vol-8, No3,30-35

Simeon D, Spiegel D, Loewenstein RJ, Lewis-Fernández R, Sar V, Vermetten E, Cardeña E, Dell PF: (2018). Dissociative disorders in DSM-5. Sep 2018:28(9):824-852. Doi: 10.1002/da.20874.

Spiegel, D. (2018). Trauma and dissociation implications for borderline personality disorder. Current Psychiatry Reports. 2018;16 (2):434 -440. Doi:10.1007/s11920-013-04348 .

Steven K. Thompson., (2012). Sampling' $3^{\text {rd }}$ ed, John Wiley \& Sons, p59-60.

Vermetten, E. (2018). Trauma and dissociation implications for borderline personality disorder. Current Psychiatry Reports. 2018;16 (2):434 -440. Doi:10.1007/s11920-013-0434-8.

World Health Organization, (2020). Adolescent health and development. Available at https://www.who.int/ westernpacific /news/q-a-detail/adolescenthealth-and-development. 


\section{الاضطر ابات الانفصالية وعلاقتها بالضغط النفسي لاى المراهقين \\ ايمان احمد شلبى الخياط ـ منى حسن عبد العال- ضحى عبد البصير محمود}

الاضطراب الانفصالي عند المراهقين غالبا مايعرف بأنه مرتبط بأحداث الحياة المجهدة. غالبًا ما يكون الاضطر اب الانفصالى هو الاستجابة النفية للاحداث المؤلمه. على الرغم من أن الأحداث المؤلمة ليست كلها

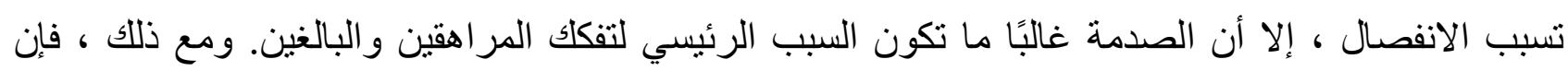
المر اهقين أكثر عرضة للصدمات لأن عقليتهم لا تزال في طور النمو ولا يتمتعون بعد بالمرونة النفسية التي يتمتع بها البالغون. أسسهم العاطفية والنفسية مهتزة بالفعل ، مما يجعلهم عرضة للانفصال في حالة حدوث صدمة.لذا تهذف هذه الدراسة إلى التعرف على الاضطرابات الإنفصالية وعلاقتها بالضغط النفسي لدى المر اهقين. وقد اجريت هذه الدراسة على (OVY) طالب من طلبه الفرقه الاولى بكليه التمريض بجامعة بنها بمدينة بنها. وقد أوضحت هذه الدراسة على وجود علاقة ارتباط موجبة معنوية بين الاضطراب الانفصالى هري الكلي واضطراب التونر الكلي لديهم ـ وقد اوصت هذه الدراسه بتقديم برنامج نفسي تربوي يركز على ملى الاحتياجات النفسية و الفسيولوجية و الاجتماعية للمر اهقين 